\title{
Dr. Hugo René Paganini (1959 - 2010)
}

C uando me invitaron a expresar mis reflexiones sobre el Dr. Hugo Paganini para prologar esta obra, creí importante, antes de profundizar en las características del ser humano, repasar su vida profesional. Para ello, simplemente me permito invitar al lector a recorrer su curriculum, tan bien denominado la "hoja de vida".

\section{Curriculum Vitae resumido}

\section{Títulos profesionales}

- Médico, otorgado por la Universidad de Buenos Aires el 16/12/83. Promedio general de la carrera: 7,93 .

- Médico Pediatra, otorgado por la Sociedad Argentina de Pediatría.

- Médico Pediatra, otorgado por el Ministerio de Salud y Acción Social de la Nación.

- Médico Pediatra Infectólogo, otorgado por la Sociedad Argentina de Pediatría.

- Médico Infectólogo, otorgado por la Sociedad Argentina de Infectología.

- Médico Infectólogo, certificado por el Consejo de Certificación de la Academia Nacional de Medicina.

- Médico Pediatra Infectólogo, certificado por el Consejo de Certificación de la Academia Nacional de Medicina.

\section{Cargos asistenciales}

- Médico asistente del Servicio de Control Epidemiológico e Infectología, Hospital Nacional de Pediatría "Prof. Dr. Juan P. Garrahan” (1991-2000).

- Médico principal del Servicio de Control Epidemiológico e Infectología, Hospital Nacional de Pediatría "Prof. Dr. Juan P. Garrahan” (2000-2010).

- Coordinador infectológico de la Unidad de Trasplante de Médula Ósea, Hospital Nacional de Pediatría "Prof. Dr. Juan P. Garrahan” (1994-2010).

- Médico Infectólogo Pediatra de FUNCEI (Fundación del Centro de Estudios Infectológicos), Presidente: Dr. Daniel Stamboulian (1989-2010).

\section{Actividad en sociedades científicas}

- Miembro titular de la Sociedad Argentina de Pediatría.

- Miembro titular de la Sociedad Argentina de Infectología.

- Miembro titular de la Sociedad Latinoamericana de Infectología Pediátrica.

- Vocal de la Comisión Directiva de la Sociedad Argentina de Infectología.

- Secretario de la Comisión Directiva de Sociedad Argentina de Infectología.

- Vocal suplente de la Comisión Directiva de Sociedad Argentina de Infectología.

- Miembro de la Comisión de Infectología Pediátrica de la Sociedad Argentina de Infectología.

- Secretario de la Sociedad Argentina de Infectología Pediátrica.

- Presidente del Comité de Infecciones del Niño Inmunocomprometido de la Sociedad Latinoamericana de Infectología Pediátrica.

\section{Participación en comités editoriales y referatos}

- Revisor de Archivos Argentinos de Pediatría.

- Revisor de la revista Cancer, American Academy of Cancer.

- Revisor de Pediatric Drugs.

- Experto invitado en SIIC.

- Revisor del American Journal of Respiratory Medicine.

- Revisor del Journal of Clinical Oncology. 


\section{Publicaciones y actividad docente}

- Trabajos presentados en congresos: 156.

- Trabajos publicados en revistas científicas y libros: 125 (23 en Medline).

- Libros editados: 9.

- Cursos dictados: 38.

- Participación como expositor, panelista, moderador o coordinador en simposios, congresos y otras reuniones científicas: 390.

- Premios recibidos: 13 .

Indudablemente, quienes no conocían sus antecedentes, comprenderán el merecido reconocimiento a la intensidad, dedicación y pasión que caracterizó la vida profesional de Hugo Paganini.

A un currículum que no requiere más comentarios, creo importante agregarle dos reflexiones personales. En primer lugar, destacar a Hugo alumno, y la trascendencia en su carrera de lo aprendido con uno de sus grandes maestros, el Dr. Daniel Stamboulian, en cuanto al abordaje profesional de la especialidad desde tres áreas: la asistencia, la docencia y la investigación aplicada, en las cuales Hugo trabajó y se desarrolló de manera intensa y continua.

Un claro ejemplo de la aplicación de este aprendizaje fue su tarea en la atención de niños con cáncer e infecciones, llevada a cabo fundamentalmente en el Hospital Nacional de Pediatría “Prof. Dr. Juan P. Garrahan”, su segundo hogar. Allí, donde se asisten aproximadamente a 30\% de los niños con cáncer en la Argentina y se atienden más de 400 episodios de neutropenia y fiebre cada año, en el plano asistencial Hugo logró estandarizar la atención infectológica de estos pacientes y obtener los mejores resultados. En materia de investigación, desarrolló estudios como los relacionados con los factores de riesgo de mortalidad de los niños inmunocomprometidos con infecciones, buscando generar prácticas para reducir su morbi-mortalidad. En la docencia, compartió sus conocimientos en el tema de manera continua y logró por ello un destacado lugar como especialista tanto a nivel nacional como internacional.

El trabajo en niños neutropénicos febriles lo llevó a ser reconocido por sus colegas como un referente en el tema. Este consenso sobre el Manejo de la Neutropenia y Fiebre es un ejemplo más, seguramente fruto de mucho esfuerzo, sostenido por la convicción de la importancia de compartir el conocimiento. Precisamente la segunda reflexión tiene que ver con Hugo "Maestro" con letras mayúsculas. Incondicional, convencido de que para lograr el aprendizaje de conceptos y herramientas útiles para la práctica diaria del pediatra es válido aplicar tanto metodologías convencionales como educación informal, Hugo caminó la vida haciendo docencia en cada instancia en que le fue posible, y esta actitud lo plasmó como líder indiscutido entre sus alumnos y pares.

Hugo amigo. Quienes tuvimos el enorme placer y la suerte de tenerlo en ese plano de la vida, compartiendo con “el Paga” no sólo horas de trabajo sino una profunda amistad, nos enorgullecemos recordándolo por su simpleza, su transparencia, su fantástico sentido del humor, su particular capacidad de individualizar a sus amigos y sostener con cada uno un vínculo diferente y único.

Uno de los más destacados especialistas de la Infectología Pediátrica de Argentina y América Latina preparó este trabajo poco antes de su fallecimiento, aprovechemos esta nueva oportunidad de aprendizaje que esta obra nos presenta.

Muchas gracias.

Roberto Debbag

Director Médico para Latinoamérica

Sanofi Pasteur S.A. 